\title{
OPINIÃO LEGAL: DA IMPOSSIBILIDADE DE INVESTIGAÇÃO DO PRESIDENTE DA REPÚBLICA
}

\section{LEGAL OPINION: THE INVESTIGATION INDEPENDENT OF THE PRESIDENT OF THE REPUBLIC}

Ives Gandra da Silva Martins;

\begin{abstract}
Professor Emérito da Universidade Mackenzie, em cuja Faculdade de Direito foi Titular de Direito Constitucional e Econômico e Doutor em Direito, Professor Emérito da UNIP, UNIFIEO, UNIFMU, do CIEE/O ESTADO DE SÃO PAULO, das Escolas de Comando e Estado-Maior do Exército - ECEME, Superior de Guerra - ESG e da Magistratura do

Tribunal Regional Federal - $1^{a}$ Região; Professor Honorário das Universidades Austral (Argentina), San Martin de Porres (Peru) e VasiliGoldis (Romênia); Doutor Honoris Causa das Universidades de Craiova (Romênia) e das PUCs-Paraná e Rio Grande do Sul, e Catedrático da Universidade do Minho (Portugal), Fundador e Presidente Honorário do Centro de Extensão Universitária - CEU- Escola de Direito. E-mail: ivesgandra@gandramartins.adv.br
\end{abstract}

Samantha Ribeiro Meyer-Pflug Marques

Professora Titular de Direito Constitucional da Faculdade de Direito da Universidade Nove de Julho, Doutora e Mestre pela Faculdade de Direito da PUC-SP.

E-mail: samanthameyer@uol.com.br

Convidados

RESUMO: A Constituição Federal de 1988 ao instituir o Estado Democrático de Direito e adotar o sistema presidencialista, dedicou especial atenção a figura do Presidente da República, que acumula as funções de Chefe de Estado e de Governo. Nesse sentido, ao tratar da responsabilidade do Presidente da República é expressa ao instituir uma cláusula de imunidade relativa, na medida em que não permite que ele venha a ser responsabilizado por atos estranhos a sua função no exercício do mandato. A finalidade precípua do referido dispositivo constitucional não é outra senão a de garantir a governabilidade e a estabilidade das instituições. A questão que se coloca reside em saber se essa impossibilidade de responsabilizar o Presidente durante a vigência do seu mandato por atos estranhos a sua função engloba também a impossibilidade de o investigar, ou seja, a instauração de um inquérito.

Palavras-Chave: Estado Democrático de direito; Responsabilidade do Presidente da República; Imunidade penal relativa.

ABSTRACT: The Federal Constitution of 1988, when establishing the Democratic State of Law and adopting the presidential system, paid special attention to the figure of the President of the Republic, who accumulates the functions of Head of State and Government. In this sense, when dealing with the responsibility of the President of the Republic is expressed when establishing a clause regarding irresponsibility, in that it does not allow him to be held accountable for acts that are extraneous to his role in the exercise of the mandate. The primary purpose of this constitutional provision is to ensure governance and stability of institutions. The question arises as to whether this impossibility of holding the President accountable for the duration of his term 
of office by acts unconnected with his function also implies the impossibility of investigating him, that is, the initiation of an investigation

Keywords: Democratic state; Responsibility of the President of the Republic; Relative criminal immunity.

SUMÁRIO: I - Da Consulta; II- Da Imunidade Penal Processual do Presidente da República.

\section{I - DA CONSULTA}

Em 14 de março de 2017, oentão Procurador Geral da República, Rodrigo Janot, requereu a abertura de investigações (Inquérito $\mathrm{n} .^{\circ} 4.462 / \mathrm{DF}$ ) sobre fatos relacionados ao Ministro Chefe da Casa Civil, Eliseu Lemos Padilha e ao Ministro da Secretaria-Geral da Presidência da República, Wellington Moreira Franco, em razão das declarações prestadas pelos colaboradores José de Carvalho Filho, Cláudio Melo Filho, Marcelo Bahia Odebrecht, Benedicto Barbosa da Silva Júnior, Hilberto Mascarenhas Alves da Silva Filho e Paulo HenyanYueCesena.

A inicial refere-se a uma solicitação no valor de quatro milhões de reais feita por Moreira Franco, então Ministro Chefe da Secretaria de Aviação Civil - a pretexto da campanha eleitoral de 2014-ao Grupo ODEBRECHT, em troca de ver os seus pleitos atendidos por ocasião do Edital da segunda rodada de concessões aeroportuárias. O pagamento, por sua vez, teria sido realizado ao Sr. Eliseu Padilha, pessoa indicada por Moreira Franco para receber os citados recursos.

Consta, ainda da inicial, a menção a um jantar, no qual teriam participado Marcelo Odebrecht, Claudio Melo Filho, Eliseu Padilha e o então Vice-Presidente da República, Michel Temer, ocorrido no dia 28 de maio de 2014, no Palácio do Jaburu. Nesse jantar teria sido solicitado, a pretexto da campanha eleitoral de 2014, o repasse de dez milhões de reais. O delator Marcelo Odebrecht declara que do montante desses recursos,seis milhões de reais seriam destinados à campanha do Paulo Skaf e quatro milhões de reaisao Eliseu Padilha.

Na petição do Chefe do Ministério Público Federalrequer-se a abertura de investigação apenas em face de Eliseu Lemos Padilha e Wellington Moreira Franco, excluindo o Presidente Michel Temer em virtude da imunidade temporária à persecução penal a que faz jus, disposto no art. 86, $\S 4^{\circ}$ da Constituição Federal de 1988. No entender do Procurador Geral da República isso implica a "impossibilidade de investigação do Presidente da República, na vigência de seu mandato, sobre atos estranhos ao exercício de suas funções". 1

O Ministro Relator do Supremo Tribunal Federal Edson Fachin, em 17 de abril de 2017, proferiu decisão no sentido de acatar em sua totalidade a inicial do Procurador Geral da República e autorizar a investigação apenas e tão somente em relação aos Srs. Eliseu Padilha e Wellington Moreira Franca, excluindo o Presidente Michel Temer por força do disposto no $\S 4^{\circ}$ do art. 86 da Constituição de $1988 .^{2}$

Em 17 de setembro de 2017 toma posse a nova Procuradora Geral da República, Raquel Dodge, e cinco meses após, em 26 de fevereiro de 2018, requer ao Supremo Tribunal Federal a inclusão do Presidente da República Michel Temer no Inquérito n. ${ }^{\circ}$ 4.462/DF - já em andamentoque investiga o suposto repasse de dez milhões de reais da Empresa da Odebrecht ao MDB, em 2014, bem como a prorrogação do inquérito por mais sessenta dias.

No entendimento da Procuradora-Geral da República, o disposto no art. $86, \S 4^{\circ}$ da Constituição Federal, demanda nova interpretação a qual não impediria a investigação do

\footnotetext{
${ }^{1}$ Petição do Procurador Geral da República no Inquérito n. ${ }^{\circ}$ 4.462/DF, 14/03/2017, Supremo Tribunal Federal, Relator Ministro Edson Fachin, fl. 55

${ }^{2}$ Decisão proferida em 04 de abril de 2017 pelo Ministro Relator Edson Fachin no Inquérito n. ${ }^{\circ} 4.462 / \mathrm{DF}$ do Supremo Tribunal Federal.
} 
Presidente da República por atos estranhos ao mandato e "os fatos narrados pelos colaboradores e os elementos de corroboração que trouxeram reclamam a investigação imediata". 3

O relator Ministro Edson Fachin do Supremo Tribunal Federal, proferiu decisão, em 2 de março de 2018, acatando o pedido da Procuradora - Geral da República para incluir o Presidente da República no âmbito da investigação e prorrogar o inquérito por sessenta dias. Para o Ministro Edson Fachin: "a investigação do Presidente da República não afronta a Carta Magna". Alega, ainda que: "a instauração de inquérito não implica qualquer responsabilização do investigado."

Aquestão que se formula consiste em saber se a impossibilidade de responsabilizar o Presidente da República por atos estranhos ao exercício das suas funções prevista expressamente no $\S 4^{\circ}$ do art. 86 da Constituição Federal de 1988 proíbe também a instauração de investigação contra o Presidente da República.

\section{II- DA IMUNIDADE PENAL PROCESSUAL DO PRESIDENTE DA REPÚBLICA}

O Governo republicano tem como uma de suas características precípuas o estabelecimento na Constituição Federal de limitações ao exercício do poder e a responsabilização, civil, penal, administrativa e política de todos os agentes públicos, inclusive do Presidente da República, por violação às normas vigentes.

Deste modo, encontra-se prevista na Constituição Federal de 1988 a possibilidade de responsabilização do Presidente da República, seja pela prática de infração penal comum ou pela prática de crime de responsabilidade, com a aplicação das sanções cabíveis, inclusive a possibilidade de suspensão e perda de mandato. (arts. 85 e 86 da CF/88)Assevera Geraldo Brindeiro que:

"No presidencialismo, o Presidente da República, como Chefe de Estado e de Governo, pode ser responsabilizado não apenas criminalmente, mas também politicamente." 5

No entanto, a Constituição Federal de 1988 traz em seu texto uma hipótese na qual se veda expressamente a responsabilização do Presidente da República durante o mandato. Ela está insculpida no $\S 4^{\circ}$ do art. 86 , in verbis:

Art. 86 .

$\S 4^{\circ}$ O Presidente da República, na vigência de seu mandato, não pode ser responsabilizado por atos estranhos ao exercício de suas funções.(grifos nossos)

Trata-se de um impedimento à responsabilização do Presidente da República por "atos estranhos ao exercício de suas funções", ou seja, atos cometidos que não guardam relação com o exercício das funções presidenciais. Esses atos podem ter sido cometidos antes da sua posse no cargo de Presidente ou até mesmo durante o mandato, desde que não guardem relação com o exercício de suas funções. Preleciona Geraldo Brindeiro que:

\footnotetext{
${ }^{3}$ Petição da Procuradora Geral da República, de 26/02/2018 no Inquérito n. ${ }^{\circ}$ 4.462/DF Supremo Tribunal Federal, Relator Ministro Edson Fachin, p. 4

${ }^{4}$ Decisão monocrática proferida pelo Relator Ministro Edson Fachin do Supremo Tribunal Federalno Inquérito n. ${ }^{\circ}$ 4.462/DF em 01 de março de 2018.

5 BRINDEIRO, Geraldo, “Artigos 85 e 85” In. Comentários à Constituição Federal de 1988. Coordenadores: Paulo Bonavides, Jorge Miranda e Walber de Moura Agra. Rio de Janeiro: Forense, 2009, p. 1124.
}

Revista de Direito Brasileira | São Paulo, SP | v. 19 | n. 8 | p. 419 - 430 |Jan./Abr. 2018 
"A imunidade alcança, assim, as infrações penais comuns praticadas antes da investidura no cargo e aquelas cometidas na vigência de seu mandato mas estranhas às funções presidenciais."6

Isso está a significar que ele somente responde por atos que guardem estrita relação com o exercício do mandato, ou seja, com a função conferida ao cargo de Presidente da República dentro da Administração Pública. Nesse sentido, por ocasião da publicação dos Comentários à Constituição de 1988 se manifestaram Celso Ribeiro Bastos e esse primeiro escritor que:

"O certo é que, durante a vigência do mandato, não pode ser o Presidente da República responsabilizado, fora das expressas previsões constitucionais, por atos estranhos a sua função.

Por vigência há que se compreender a inteireza do mandato, mesmo que suspenso o Presidente de suas funções. É que durante a suspensão da função, o mandato continua a viger, e o Presidente da República continua a ser Presidente da República, mesmo com suas funções suspensas."7

Nesse contexto, há que se levar em consideração a posição do Presidente da República, queocupa o mais alto cargo da Administração Pública e exerce as relevantes funções de Chefia de Estado e Chefia de Governo, uma vez que vigora o sistema presidencialista no Brasil.

Está-se diante de uma prerrogativa de caráter institucional, na exata medida em que se impede a responsabilização do Presidente da República durante apenas a vigência do mandato, por infrações estranhas à função, abrangendo as ocorridas antes ou até mesmo depois da posse no cargo. Após o final do mandato responderá integralmente o Presidente da República pelas eventuais infrações cometidas perante a justiça comum.

É justamente o que ocorre no caso em tela em que se imputa ao Presidente da República a suposta prática de infrações ocorridas em 2014, assim sendo anteriores ao exercício do mandato de Presidente da República. Parece não restarem dúvidas que as acusações recaem sobre atos estranhos a função de Presidente, eis que a Presidência da República à época (2014) era exercida pela Sra. Dilma Rousseff.

Trata-seda prática de suposta infração estranha a função de Presidente da República, portanto integralmente abrangido pela regra constante do $\S 4^{\circ}$ do art. 86 da Constituição Federal de 1988.

Verifica-se que faz o Texto Constitucional uma distinção nítida entre as infrações cometidas que guardam relação com o exercício da função e aquelas que não guardam relação com a função, para impedir que a responsabilização dessas infrações estranhas ao exercício do cargo cause instabilidade política e comprometa o relevante mister exercido pelo Presidente da República.

Interessante registrar que a Constituição Brasileira não é a única Constituição a contemplar a irresponsabilidade do Presidente durante o mandato por atos estranhos a sua função. Levando em consideração a condição de órgão constitucional e de Chefe de Estado que exerce as mais relevantes funções estatais, diversas Constituições conferem prerrogativas ao Presidente da República que não são concedidas aos demais cargos e funções da República. ${ }^{8}$ As Constituições portuguesa, italiana e francesa, por exemplo, também tratam da questão.

\footnotetext{
${ }^{6}$ BRINDEIRO, Geraldo, “Artigos 85 e 85” In. Comentários à Constituição Federal de 1988. Coordenadores: Paulo Bonavides, Jorge Miranda e Walber de Moura Agra. Rio de Janeiro: Forense, 2009, p.1147.

${ }^{7}$ MARTINS, Ives Gandra da Silva; BASTOS, Celso Ribeiro. Comentários à Constituição do Brasil, São Paulo: Saraiva, vol4, tomo II, $3^{\circ}$ ed., 2002, p. 468.

${ }^{8}$ Cf. DI RUFFIA, Paolo Biscaretti. Direito Constitucional- Instituições de Direito Público. Tradução de Maria Helena Diniz. São Paulo: Revista dos Tribunais,1972, p. 381. 
A Constituição de Portugal de 1976 estabelece no $§ 4^{\circ}$ do art. 133 que:

Art.133

(...)

$\S 4^{\circ}$ Por crimes estranhos ao exercício de suas funções o Presidente da República responde depois de findo o mandato perante os tribunais comuns. (grifos nossos)

Embora a Constituição portuguesa já tenha sofrido diversas revisões tal dispositivo restou inalterado, tendo em vista sua relevância dentro do sistema semi-presidencialista português.

A Constituição da Itália de 1947 dispõe em seu art. 90 que:

Art. 90. O Presidente da República não é responsável pelos atos cumpridos no exercício das suas funções, exceto por alta traição ou por atentado à Constituição. Nesses casos é colocado em estado de acusação pelo Parlamento em sessão comum, com a maioria absoluta dos seus membros.

Já a Constituição Francesa de 1958 é mais explícita que a portuguesa e a italiana ao estabelecer expressamente que o Presidente da República não pode ser objeto de investigação e ação penal, in verbis:

ARTIGO $67^{\circ} \mathrm{O}$ Presidente da República não é responsável pelos atos realizados nessas funções, sujeito às disposições dos artigos 53-2 e 68.

Não pode, durante o seu mandato e perante nenhum órgão jurisdicional ou autoridade administrativa francesa, ser convocado a depor, bem como ser objeto de uma ação, um ato de informação, de investigação ou de acusação. Qualquer prazo de prescrição ou caducidade é suspenso.

As instâncias e procedimentos aos quais assim é feito obstáculo podem ser retomadas ou contratadas contra ele à expiração de um prazo de um mês após a cessação das funções." (grifos nossos)

Ao se levar a cabo uma interpretação teleológica e sistemática dodisposto no $\S^{\circ}$ do art. 86 da Constituição verifica-se que o objetivo da norma não é outro senão o de garantir a governabilidade do País e proteger a estabilidade política, econômica e social, como bem maior a ser tutelado pelo ordenamento jurídico.

Não há negar-se que num regime presidencialista como o brasileiro, tudo está centralizado na figura do Presidente da República, qualquer incidente em torno dele acaba por ter repercussão nacional e gerar instabilidade institucional, econômica e política. Por essa razão optou o Texto Constitucional por preservar o Presidente da República da responsabilização por atos estranhos a sua função durante o mandato, quer na fase investigativa, quer na fase processual.

Essa preocupação da Constituição da República com a governabilidade do País e a estabilidade institucional se faz presente inclusive nas hipóteses em que ela admite a responsabilização do Presidente da República, na exata medida em que exige a autorização de dois terços da Câmara dos Deputados para dar início ao processo, no Senado Federal no caso do crime de responsabilidade e no Supremo Tribunal Federal na hipótese de infração penal comum.

Em outras palavras mesmo quando prevista a responsabilização do Presidente da República impõe o Texto Constitucional a necessidade de expressa autorização da Câmara dos Deputados para processá-lo, ou seja, busca-se de um lado evitar que o Presidente da República seja alvo de pleitos infundados e lides temerárias, bem como impedir que a instabilidade se instaure no País, causando prejuízos incalculáveis e irreversíveis para toda a sociedade. 
Há que se levar em consideração que a autorização para processar o Presidente, seja nos crimes de responsabilidade, seja nas infrações penais comuns geram graves consequências políticas, econômicas e sociais, pois implicam no afastamento do Presidente de suas funções por cento e oitenta dias e até mesmo na perda de seu mandato.

A grande maioria dessas consequências se mostra irreversível do ponto de vista jurídico, econômico e político. Foi justamente para se evitar esse afastamento por atos estranhos ao mandato é que o constituinte optou pela impossibilidade de se responsabilizá-lo por atos estranhos a sua função durante o mandato e assim garantir a continuidade da Chefia do Estado e do Governo.

A impossibilidade de se responsabilizar o Presidente da República por atos estranhos ao mandato abarca tanto a ação penal em si, como o processo de investigação. Não se apresenta razoável que se pudesse investigar o Presidente da República por atos estranhos ao mandato, para ao fim e ao cabo não ser possível ingressar com a ação penal contra ele. Estar-se-ia colocando um Presidente da República, legitimamente eleito a mercê de pleitos infundados e lides temerárias e comprometendo o desempenho de seu relevante e difícil tarefa que é a Chefia de Governo e de Estado.

Ora, se o objetivo da norma constitucional é impedir que o Presidente da Repúblicasofra as consequências de uma ação penal por atos que não guardam relação com o seu mister, tendo em vista a necessidade de se garantir a estabilidade das instituições e a governabilidade do País.

Não seria lógico, nem razoável autorizar que ele sofresse todos os estigmas de uma investigação criminal, que o País passasse por toda a instabilidade e crise política que e econômica que uma situação como essa acarreta para ao final restar o Ministério Público impedido de oferecer a eventual denúncia e o Supremo Tribunal Federal igualmente impedido de recebê-la por força do $\S 4^{\circ}$ do art. 86 da Constituição Federal. Ou ainda, que restasse comprovada na investigação criminal a inexistência da prática delituosa.

A interpretação de qualquer dispositivo constitucional deve levar em consideração o postulado da unidade da Constituição segundo o qual as normas da Constituição devem ser interpretadas de maneira sistemática e consideradas coesas entre si. Desse modo, afasta-se a interpretação isolada de qualquer um de seus dispositivos, sob pena de levar-se a cabo contradições no Texto Constitucional. Esclarece Celso Ribeiro Bastos que:

"Ressalta aqui mais uma particularidade da interpretação constitucional relativamente à interpretação que se faça dos demais ramos do Direito. É que o denominado método 'lógico-sistêmico' costuma ser considerado com um dentre os vários métodos passíveis de serem adotados pelo intérprete, na interpretação em geral. Mas na interpretação especificamente constitucional, a consideração sistêmica do texto é imperativo decorrente da supremacia constitucional na hierarquia da pirâmide jurídica.

Acerca da interpretação sistemática, que se torna possível e imperativa no âmbito da Constituição, a partir da denominada unidade constitucional, como evidenciaria Enneccerus, pode-se dizer que recai ela sobre a norma jurídica tomada em íntima conexão com outros preceitos, com o lugar em que se acha, até que seja possível alcançar o laço que une todas as regras e instituições num todo coerente." ${ }^{9}$ (grifos nossos)

Deve-se interpretar a regra insculpida no $\$ 4^{\circ}$ do art. 86 da Constituição em consonância com as demais normas constitucionais. Assim sendo, a inteligência do aludido parágrafo deve ser realizada em face dos comandos constantes no art. 85 e no próprio art. 86

\footnotetext{
${ }^{9}$ BASTOS, Celso Ribeiro. Hermenêutica e Interpretação Constitucional. São Paulo: Celso Bastos Editor. $3^{\circ}$ ed., 2002, p. 173.
} 
que tratam da responsabilidade do Presidente da República e das demais normas constitucionais.

A Constituição disciplinou exaustivamente todas as hipóteses de responsabilização do Presidente da República, mas tratou de contemplar uma exceção, qual seja, a que versa sobre atos estranhos ao exercício da função presidencial para proteger outros valores constitucionalmente albergados, quaissejam, a livre atuação do Poder Executivo Federal, a governabilidade do País, a segurança e o equilíbrio nas relações institucionais.Tais valores só serão integralmente protegidos ao se impedir a instauração de investigação criminal e da ação penal em face do Presidente, como quer o Texto Constitucional.

Ao se conferir interpretação diversa estar-se-ia esvaziando e contrariando a própria finalidade do aludido dispositivo constitucional, de maneira a deixá-lo desprovido de qualquer eficácia.Basta se ter em vista a hipótese da instauração de uma investigação contra o Presidente da República por ato estranho a sua função, com todo o estigma e instabilidade política e econômica que geraria para o País, para depois restar comprovado que não houve crime.

O desiderato constitucional insculpido no $\S 4^{\circ}$ do art. 86 da Constituição de 1988 só será alcançado ao se vedar a instauração de investigação e ação penal contra o Presidente da República.Trata-se de uma imunidade temporal decorrente da sua qualidade de Chefe de Estado e Governo, qualquer interpretação diversa dessa acabará por violar frontalmente o preceito constitucional.

Ao se impossibilitar a instauração de inquérito policial e a persecução penal privilegia o Texto Constitucional a relevante função exercida pelo Presidente da República e a segurança e harmonia entre as instituições. De igual modo evita-se prejuízos econômicos, políticos e sociais ao País, na grande maioria das vezes, irreversíveis.

Destarte, cumpre observar que esse é o entendimento predominante na Procuradoria Geral da República. Vale dizer que o Procurador Geral da República já havia se manifestado expressamente nesse sentido, na Petição n. ${ }^{\circ}$ 5.263, de 03 de março de 2015, que versava sobre a investigação da então Presidente Dilma Rousseff na "Operação Lava Jato" nos seguintes termos:

“(...) há total impossibilidade de investigação do Presidente da República, na vigência de seu mandato, sobre atos estranhos ao exercício de suas funções.

(...)

Portanto, como assentado pelo Supremo Tribunal Federal, não há viabilidade jurídica para apuração dos fatos em detrimento da Presidente da República." (grifos nossos) $)^{10}$

Em conformidade com essa intepretação se manifestou o relator Ministro Teori Zavascki ao acatar integralmente o pedido de arquivamento do Chefe do Ministério Público Federal em relação a Presidente da República, Dilma Rousseff por se tratar de ato estranho ao exercício do mandato, nos seguintes termos:

"Portanto, a rigor, nada há a arquivar em relação à Presidente da República. Aliás, ainda que assim não fosse, é certo que, nos termos da Constituição Federal, "o Presidente da República, na vigência de seu mandato, não pode ser responsabilizado por atos estranhos ao exercício de suas funções" (CF, art. 86, § $\left.4^{\circ}\right){ }^{11}$

\footnotetext{
${ }^{10}$ Petição n. ${ }^{\circ}$ 5.263, de 03 de março de 2015 do Procurador Geral da República Rodrigo Janot no Supremo Tribunal Federal. Relator Ministro Teori Zavascki, fls. 24-30.

${ }^{11}$ Decisão proferida pelo Ministro Teori Zavascki do Supremo Tribunal Federal na Petição n, ${ }^{\circ}$ 5.263/DF, em 06 de março de 2015, p. 3. http://www.stf.jus.br/portal/autenticacao/ sob o número 7973314. PET 5263 / DFp. 3.
}

Revista de Direito Brasileira | São Paulo, SP | v. 19 | n. 8 | p. 419 - 430 |Jan./Abr. 2018 
No caso em tela também foi esse o entendimento exarado pelo então Procurador-Geral da República, Rodrigo Janot ao solicitar a abertura de investigação em face dos Ministros Eliseu Padilha e Moreira Franco e excluir o Presidente Michel Temer. Em sua petição ele reconhece que:

“(...) há menção de participação do atual Presidente da República Michel Temer, sendo certo que ele possui imunidade temporária à persecução penal". ${ }^{12}$

Prossegue em seu pensamento ao explicitar que a regra constante do $\S 4^{\circ}$ do art. 86 do Texto Constitucional significa a:

“(...) impossibilidade de investigação do presidente da República, na vigência de seu mandato, sobre atos estranhos ao exercício de suas

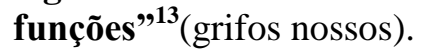

Também não foi outra a posição adotada pelo Relator Ministro Edson Fachin ao se manifestar nos autos em decisão monocrática, de 04 de abril de 2017, e acatar em sua totalidade o pedido do Chefe do Ministério Público Federal de não abrir investigação em face do Presidente da República por força do $§ 4^{\circ}$ do art. 86 do Texto Constitucional.

Nesse particular, causa estranheza a mudança de interpretação da Chefe do Ministério Público Federal ao solicitar a instauração de procedimento de investigação em face do Presidente da República nos autos do Inquérito n. ${ }^{\circ} 4.462 / \mathrm{DF}$, tendo em vista que o próprio Ministério Público Federal e o Supremo Tribunal Federal já tinham apreciado a questão. Também não restou demonstrada na inicial a justificativa para a adoção da mudança na interpretação do dispositivo constitucional, nem qualquer alteração de paradigma que suscitasse a necessidade de revisão da inteligência da norma sub examine.

Quer nos parecer que essa não é a melhor interpretação a ser empregada ao dispositivo constitucional em apreço, e nem aquela que se coaduna aos princípios e valores albergados pelo Texto Constitucional. Adverte, nesse particular, Celso Ribeiro Bastos que:

"Cada norma subsume-se e complementa-se com princípios constitucionais, nele procurando encontrar seu perfil último." 15

É imprescindível quando se interpreta qualquer norma constitucional se ater a finalidade contida nela, ou seja, qual foi o intuito da Constituição ao regulamentar tal situação, quais foram os princípios por ela protegidos.

Nesse diapasão, uma leitura detida do $\$ 4^{\circ}$ do art. 86 leva indubitavelmente a conclusão de que a finalidade do Texto Constitucional não foi outra senão a de garantir a governabilidade do País, a estabilidade institucional, e deste modo evitar crises que trazem graves consequências econômicas, políticas e sociais para todos.

\footnotetext{
${ }^{12}$ Petição do Procurador Geral da República no Inquérito n. ${ }^{\circ}$ 4.462/DF, 14/03/2017, Supremo Tribunal Federal, Relator Ministro Edson Fachin, fl. 55

${ }^{13}$ Petição do Procurador Geral da República no Inquérito n. ${ }^{\circ}$ 4.462/DF, 14/03/2017, Supremo Tribunal Federal, Relator Ministro Edson Fachin, fl. 55

${ }^{14}$ Decisão proferida em 04 de abril de 2017 pelo Ministro Relator Edson Fachin no Inquérito n. ${ }^{\circ}$ 4.462/DF do Supremo Tribunal Federal.

${ }^{15}$ BASTOS, Celso Ribeiro. Hermenêutica e Interpretação Constitucional. São Paulo: Celso Bastos Editor. 3ed., 2002, p. 175.
} 
Isso não está a significar de maneira alguma que o Presidente da República diante da vedação de ser investigado ou processado por atos estranhos a sua função vá permanecer impune em caso de posterior comprovação desses atos. Pelo contrário, o Texto Constitucional é enfático ao estabelecer que ele responderá por seus atos findo o mandato e perante a justiça comum, na qualidade de cidadão.

Ademais, ao se levar a efeito uma interpretação literal do teor do $\$ 4^{\circ}$ do art. 86 chegase igualmente a conclusão de que a impossibilidade de responsabilização do Presidente da República engloba tanto a ação penal, como a investigação.

O Texto Constitucional utiliza a expressão "responsabilizado" que significa "tornar responsável"16 ou "imputar responsabilidade" que provêm de responsabilizar, responder. Impede-se que o Presidente responda por atos estranhos ao mandato, nesse particular, responder envolve tanto a fase de investigação, como a processual. Ele está impedido de responder por atos estranhos a suas funções, seja na fase investigativa, seja na fase processual.

Proíbe enfaticamente o Texto Constitucional que uma investigação ou ação penal por atos estranhos ao mandato tornem o Presidente da República vulnerável politicamente e ocasionem uma crise política com consequências irreversíveis para o País. Quer a Constituição Federal indubitavelmente evitar o estigma e a crise institucional que a instauração de uma investigação contra o Presidente da República ocasiona para ao final, por exemplo, chegar-se a conclusão de que não houve crime. Objetiva a Constituição impedir a indesejável ocorrência de pleitos infundados e lides temerárias.

Interessante salientar que aprópria Procuradora Geral da República faz referência expressa à instabilidade que uma investigação contra o Presidente da República representa institucional e politicamente ao reconhecer que:

"A investigação penal, todavia, embora traga consigo elevada carga estigmatizante, é meio de coleta de provas que podem desaparecer, de vestígios que podem se extinguir com a ação do tempo, de ouvir testemunhas que podem falecer, de modo que a investigação destina-se a fazer a devida reconstrução dos fatos e a colecionar provas. A ausência da investigação pode dar ensejo a que as provas pereçam". ${ }^{17}$ (grifos nossos)

$\mathrm{O} \S 4^{\circ}$ do art. 86 é um dispositivo constitucional que visa a proteger o cargo em si, tendo em vista todas as dificuldades de se governar um País e manter a estabilidade das instituições republicanas. Protege-se o Presidente da República durante a vigência de seu mandato de fatos estranhos ao exercício de sua função que possam prejudicar, sobremaneira, o conceito do Chefe de Estado e de Governo e inviabilizar seu governo.

Trata-se de resguardar a figura do Presidente da República, colocando-o a salvo de investigações e processos por atos estranhos ao exercício de suas funções.

$\mathrm{O}$ argumento utilizado de que se trata de uma cláusula que confere impunidade ou imunidade absoluta ao Presidente da República também não merece prosperar, na exata medida em que do ponto de vista jurídico não há impunidade: uma vez findo o mandato será instaurada a investigação contra o Presidente da República, e responderá ele se for o caso perante a justiça comum como qualquer cidadão.

É preciso deixar claro que não se está diante de uma imunidade material penal ou de uma cláusula de plena irresponsabilidade que coloca o Presidente da República acima da lei.

\footnotetext{
${ }^{16}$ Dicionário Aurélio de Português Online. Publicado em: 2016-09-24, revisado em: 2017-02-27. Disponível em: 〈https://dicionariodoaurelio.com/responsabilizado〉. Acesso em: 01 Mar. 2018

${ }^{17}$ Petição da Procuradora Geral da República, de 26/02/2018 no Inquérito n. ${ }^{\circ}$ 4.462/DF Supremo Tribunal Federal, Relator Ministro Edson Fachin, p. 4
} 
Pelo contrário, trata-se tão-somente de uma impossibilidade temporária de investigar e processar o Presidente da República, pela pratica de atos estranhos as suas funções, cometidos antes ou no curso do mandato. Nesse sentido cita-se trecho do acórdão do Supremo Tribunal Federal de relatoria do Ministro Sepúlveda Pertence:

“ O que o art. 86, $\S 4^{\circ}$, confere ao Presidente da República não é imunidade penal, mas imunidade temporária à persecução penal: nele não se prescreve que o Presidente é irresponsável por crimes não funcionais praticados no curso do mandato, mas apenas que, por tais crimes, não poderá ser responsabilizado, enquanto não cesse a investidura na presidência.

Da impossibilidade, segundo o art. $86, \S 4^{\circ}$, de que, enquanto dure o mandato, tenha curso ou se instaure processo penal contra o Presidente da República por crimes não funcionais, decorre que, se o fato é anterior à sua investidura, o Supremo Tribunal não será originariamente competente para a ação penal, nem consequentemente para o habeas corpus por falta de justa causa para o curso futuro do processo. 3. Na questão similar do impedimento temporário à persecução penal do Congressista, quando não concedida a licença para o processo, o STF já extraíra, antes que a Constituição o tornasse expresso, a suspensão do curso da prescrição, até a extinção do mandato parlamentar: deixase, no entanto, de dar força de decisão à aplicabilidade, no caso, da mesma solução, à falta de competência do Tribunal para, neste momento, decidir a respeito" 18

É uma regra de natureza meramente processual penal. Trata-se de uma mera condição de procedibilidade que se aplica tanto a propositura da ação penal, como a instauração da investigação criminal, uma vez que o desiderato constitucional é o de proteger a governabilidade e a estabilidade institucional, valores tão caros em um Estado Democrático de Direito.

Nesse sentido, já se manifestou o Ministro Carlos Mario da Silva Velloso:

“ Se se tem uma notitia criminis relativamente apenas ao Presidente da República, está há de ficar paralisada até que cesse o seu mandato, porque incide a cláusula de irresponsabilidade. Porém, se nos autos há notícia de crime praticado por outras pessoas, estas não estão evidentemente cobertas pela clausula de irresponsabilidade. ${ }^{19}$

É exatamente esse entendimento que prevaleceu e deve prevalecer no caso em tela, qual seja, a da total impossibilidade de se instaurar investigação ou ação penal por atos estranhos a função presidencial.A proibição de instauração de investigação contra o Presidente da República está abarcada integralmente pelo $\S 4^{\circ}$ do art. 86 da Constituição, fazendo parte da sua própria essência normativa.

Ademais, tal interpretação resultade um imperativo lógico, a saber, a congruência que deve existir entre a impossibilidade de se instaurar a ação penal por atos estranhos ao exercício da função durante o mandato e a necessidade de se assegurar a governabilidade e a estabilidade institucional.

Como restou assentado anteriormente, a impossibilidade de responsabilização prevista no $\S 4^{\circ}$ do art. 86 da Constituição de 1988 abarca tanto a instauração do inquérito, como o

\footnotetext{
${ }^{18}$ Supremo Tribunal Federal . Habeas Corpus n. ${ }^{\circ}$ 83.154/SP.Relator Min. Sepúlveda Pertence. Julgamento: 11/09/2003, Tribunal Pleno. Publicação DJ 21-11-2003

${ }^{19}$ Voto proferido pelo Min. Carlos Velloso, no Inquérito n. 672-6/DF do Supremo Tribunal Federal. Questão de ordem no Inquérito. Relator Ministro Celso de Mello. Julgamento: 16/09/1992. DJ 16-04-1993, p.289.
} 
recebimento da denúncia, pois tais atos deverão ser objeto de análise da jurisdição comum, uma vez findo o mandato presidencial.

Nesse diapasão tem-se que carece de competência originária o Supremo Tribunal Federal para autorizar futura e eventual investigação, bem como processo judicial criminal, uma vez que esses somente poderão ser deflagrados após o término do mandato do Presidente da República, pela jurisdição comum.

Ora, é o juiz de primeira instância o juiz natural para julgar o Presidente da República por atos estranhos ao mandato e não o Supremo Tribunal Federal. Por consequência lógica não cabe ao Supremo Tribunal Federal autorizar a investigação ou receber a ação penal contra o Presidente da República e nem ao Procurador- Geral da República requerer a instauração de inquérito e oferecer denúncia em face do Presidente da República, em virtude da completa e total competência constitucional originária para tanto.

Essa competência deverá ser exercida pela jurisdição comum após findo o mandato presidencial, como estabelecido explicitamente no Texto Constitucional. Vale ressaltar, nesse sentido, o voto proferido pelo Ministro Carlos Mario da Silva Velloso no Inquérito n. 672-6 /DF:

“(...) É que repito, não tem esta Corte competência para decidir a respeito do citado procedimento criminal, tendo em vista cláusula de irresponsabilidade inscrita na Constituição." 20

Em síntese, tem-se que carece ao Procurador-Geral da República e ao Supremo Tribunal Federal competência para exercer a jurisdição em relação ao Presidente da República pela prática de atos estranhos a função durante o exercício do mandato, seja em relação a instauração de inquérito ou ao recebimento da denúncia.

Vale frisar, que findo o mandato presidencial eventual investigação e persecução penal serão, em estrita observância ao princípio do juiz natural, objeto de apreciação da justiça comum.

É importante deixar claro que obstar a instauração de inquérito e de ação penal em face do Presidente da República por atos estranhos a sua função não afronta o princípio republicano previsto constitucionalmente.

Pelo contrário, é medida consentânea com a interpretação sistemática e teleológica do Texto Constitucional, ao passo que preserva a figura do Presidente da República pleitos infundados e de lides temerárias, garante a governabilidade, a estabilidade econômica e política do País e permite que findo o mandato responda ele perante a justiça comum pelas possíveis infrações cometidas, como qualquer outro cidadão.

Trata-se de levar a efeito uma interpretação lógico-sistemática do $\S 4^{\circ}$ do art. 86 da Constituição de 1988 que o coaduna com os preceitos constitucionais e que leva em consideração a necessidade de se garantir a estabilidade política, econômica e as relações entre as instituições do País, elementos imprescindíveis para a manutenção do Estado Democrático de Direito. Nesse sentido preleciona Joaquim José Gomes Canotilho:

"Daí que o intérprete deve sempre considerar as normas constitucionais não como normas isoladas e dispersas, mas sim como preceitos integradores num sistema interno unitário de normas e princípios." 21

\footnotetext{
${ }^{20}$ Voto proferido pelo Min. Carlos Velloso, no Inquérito n. 672-6/DF do Supremo Tribunal Federal. Questão de ordem no Inquérito. Relator Ministro Celso de Mello. Julgamento: 16/09/1992. DJ 16-04-1993, p.288-289.
} 
Nada mais é do que adotar uma interpretação que prestigiade um lado a governabilidade e a estabilidade institucional, princípios albergados pela Constituição da República e de outro garante a responsabilização do Presidente da República na justiça comum, uma vez findo o seu mandato.

É o nosso parecer

\section{S.M.J.}

São Paulo, 05de Março de 2018.

IVES GANDRA DA SILVA MARTINS

SAMANTHA RIBEIRO MEYER-PFLUG MARQUES

${ }^{21}$ CANOTILHO, Joaquin José Gomes. Direito Constitucional e Teoria da Constituição. $6^{\circ}$ ed., Coimbra: Almedina, p. 1210 